\title{
Respons Pertumbuhan Setek Batang Buah Naga Merah (Hylocereus costaricensis) Terhadap Pemberian Air Kelapa
}

\section{Growth Response of Stem Cuttings of Red-Fleshed Dragon Fruit (Hylocereus costaricensis) on The Application of Coconut Water}

\author{
Ulfah Lutfia*, Rugayah, Kus Hendarto, Tri D. Andalasari
}

Jurusan Agroteknologi, Fakultas Pertanian Universitas Lampung

Jl. Sumantri Brojonegoro No.1 Bandar Lampung 35145

*E-mail : $\underline{\text { Ulfah13.ul@gmail.com }}$

\begin{abstract}
This study was conducted to determine the effect of different ways of application and concentration of coconut water in affecting the growth of dragon fruit cuttings. The research was conducted in November to January 2016. The research used a randomized block design $(R B D)$ arranged as factorial (2x3) with three replications. The first factor is the way of application of coconut water (A) with $a_{1}$ : soaking and $a_{2}$ : spraying and the second factor is the concentration of coconut water $(B)$ with $b_{0}: 0 \%, b_{1}: 50 \%$, and $b_{2}: 100 \%$. Grouping based on the weight of stem cuttings of red dragon fruit. Homogeneity range between treatments were tested using the Barlet's test and aditifitas data is tested by Tukey's test. If these assumptions are met, further tested by the analysis of variance and differences in middle grades will be tested with Least Significant Difference (LSD) at 5\% level. The results showed that application of coconut water with a concentration of $50 \%$ can increase the weight of buds and amount of primary root. Treatment of application and interaction between the way and the concentration does not give any real effect on all variables observation.
\end{abstract}

Keyword : Coconut water, Consentration, Cuttings, Dragon fruit

Disubmit : 13 September 2017, Diterima : 01 Desember 2017, Disetujui :08 Desember 2017

\section{PENDAHULUAN}

Di daerah asalnya yaitu Meksiko, buah naga dinamakan pitahaya atau pitaya roja. Penduduk Negara Meksiko memanfaatkan buah naga untuk dihidangkan sebagai buah konsumsi segar. Dalam perkembangannya buah naga lebih dikenal sebagai tanaman dari Asia karena sudah dikembangkan secara besar-besaran di beberapa Negara Asia terutama Negara Vietnam dan Thailand (Tim Karya Tani Mandiri, 2010). Buah naga memiliki beragam jenis di antaranya buah naga berdaging merah dan putih, serta berdaging putih dengan warna kulit kuning. Namun, buah naga yang paling banyak disukai adalah buah naga berdaging merah karena rasanya yang lebih manis dan memiliki warna yang menarik. Buah naga juga memiliki manfaat seperti memperlancar pencernaan, mencegah kanker usus, dan menanggulangi diabetes. Buah naga memiliki banyak khasiat untuk kesehatan diantaranya penyeimbang kadar gula darah, memperkuat ketahanan ginjal, bermanfaat untuk kecantikan, menguatkan daya kerja otak, mengurangi keluhan keputihan, mencegah dan memperlancar feses. Selain itu, buah naga juga mengandung betacharotene dan antioksidan yang tinggi untuk mencegah kanker dan menangkal radikal bebas. 
Banyaknya manfaat dari buah naga berimbas pada meningkatnya kebutuhan buah naga yang cukup besar di Indonesia. Kebutuhan yang meningkat tersebut belum mampu dipenuhi oleh produsen baik di dalam negeri maupun di luar negeri. Winarsih (2007) melaporkan bahwa kebutuhan buah naga di Indonesia mencapai 200-400 ton per tahun. Kebutuhan buah naga yang dapat dipenuhi masih kurang dari 50\%. Permintaan komoditas buah naga mengalami peningkatan setiap tahunnya. Peningkatan produksi buah naga dapat dilakukan dengan perluasan daerah penanaman dan penyediaan bibit yang berkualitas sehingga dapat memenuhi permintaan pasar.

Ketersediaan bibit yang berkualitas dapat ditingkatkan melalui perbanyakan secara vegetatif, salah satunya dengan setek batang dari tanaman induk yang berkualitas, sehingga dibutuhkan usaha untuk mempercepat pertumbuhan tunas dan akar. Upaya peningkatan perkembangan setek dapat dilakukan dengan penggunaan zat pengatur tumbuh (ZPT). Pemberian ZPT pada setek dapat mendorong dan mempercepat pembentukan akar, merangsang pembentukan tunas baru, serta meningkatkan jumlah dan kualitas tunas maupun akar (Hartman et al., 1997). Zat pengatur tumbuh (ZPT) digunakan untuk mengoptimalkan pertumbuhan vegetatif dan reproduktif tanaman, misalnya auksin yang mampu merangsang pertumbuhan dan perakaran tanaman (Satria, 2011). Salah satu ZPT alami yang umum digunakan adalah air kelapa karena mudah didapatkan dan murah. Pemberian air kelapa dalam perbanyakan tanaman dimanfaatkan untuk memacu pembentukan tunas dan akar karena memiliki kandungan hormon auksin dan sitokinin (Kristina dan Syahid, 2012).

\section{BAHAN DAN METODE}

Penelitian ini dilaksanakan di dalam rumah kaca di lingkungan Jurusan Agroteknologi Universitas Lampung. Penelitian dilaksanakan pada bulan November sampai Januari 2016. Alat yang digunakan dalam penelitian ini adalah polybag, pisau, gelas ukur, timbangan, termometer, tempat perendaman, kertas label, dan penggaris. Bahan yang digunakan dalam penelitian ini adalah stek batang buah naga merah dengan panjang $25 \mathrm{~cm}$, larutan klorok, media tanam berupa campuran tanah top soil, pasir, dan kompos dengan perbandingan 1:1:1, serta air kelapa muda.

Penelitian ini menggunakan Rancangan Acak Kelompok (RAK) yang disusun secara faktorial (2x3) dengan 3 ulangan yang berfungsi sebagai kelompok. Faktor pertama adalah cara pemberian air kelapa (A) dengan $\mathrm{a}_{1}$ : perendaman dan $\mathrm{a}_{2}$ : penyiraman dan faktor kedua adalah konsentrasi air kelapa (B) dengan $\mathrm{b}_{0}: 0$ $\%, \mathrm{~b}_{1}: 50 \%$, dan $\mathrm{b}_{2}: 100 \%$. Terdapat 6 kombinasi perlakuan dan masing-masing diulang sebanyak 3 kali. Setiap unit percobaan terdapat 3 polibag sehingga total keseluruhan adalah 54 polibag.

Pengelompokkan berdasarkan bobot batang setek buah naga merah. Kelompok I merupakan bobot setek antara 46-94 g. Kelompok II merupakan bobot setek antara 97-117 g. Kelompok III merupakan bobot setek antara 119-178 g. Homogenitas ragam antarperlakuan diuji dengan uji Barlet dan aditifitas data diuji dengan uji Tukey. Apabila asumsi tersebut terpenuhi, selanjutnya, data yang telah diperoleh akan diolah dengan analisis ragam dan perbedaan nilai tengah akan diuji dengan BNT pada taraf 5\%. Parameter yang diamati adalah waktu muncul tunas, jumlah tunas, panjang tunas, bobot tunas, jumlah akar, panjang akar primer, dan bobot kering akar.

\section{HASIL DAN PEMBAHASAN}

Gambaran Umum Pertumbuhan Setek. Persentase hidup pada setek tanaman buah naga diperoleh dari jumlah setek hidup yang ditunjukkan dengan munculnya tunas. Jumlah setek yang hidup sebanyak 50 batang setek dari 54 batang setek yang ditanam. Penyebab tidak tumbuhnya 4 batang setek tersebut yaitu terjadi kesalahan dalam peletakkan tanaman karena posisi batang setek terbalik. Nilai persentase setek hidup dihitung berdasarkan (jumlah setek hidup : jumlah setek yang ditanam) x 100\%, sehingga diperoleh nilai persentase setek hidup sebesar $92,5 \%$. 
Waktu Muncul Tunas (hari setelah tanam). Hasil analisis ragam menunjukkan bahwa semua perlakuan yang diaplikasikan tidak memberikan pengaruh yang signifikan pada variabel waktu muncul tunas. Walaupun begitu, waktu muncul tunas paling cepat pada perlakuan $a_{2} b_{0}$. Hal ini dikarenakan, auksin yang terkandung dalam tanaman masih mampu mendukung pertumbuhan setek, sehingga belum membutuhkan auksin eksogen. Menurut Febrina (2009), pembentukan tunas sangat penting sebagai tahap awal pembentukan primordia daun dimana daun merupakan organ tanaman yang memiliki jumlah klorofil terbesar yang berfungsi sebagai tempat terjadinya proses fotosintesis. Rata-rata waktu muncul tunas pada setek batang buah naga merah adalah 30,49 hari (Gambar 1).

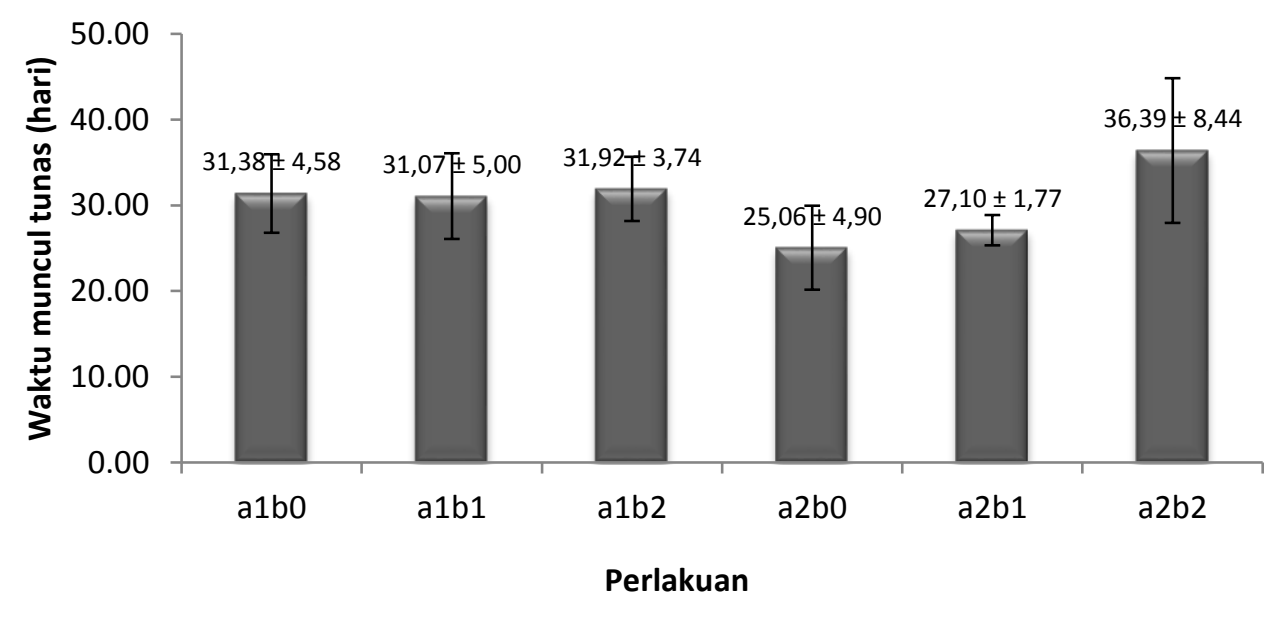

Gambar 1. Pengaruh perlakuan cara pemberian dan konsentrasi air kelapa pada waktu muncul tunas setek batang buah naga merah

Jumlah Tunas. Hasil analisis ragam menunjukkan bahwa semua perlakuan yang diaplikasikan tidak memberikan pengaruh yang signifikan pada variabel jumlah tunas. Rata-rata jumlah tunas adalah 2,33. Walaupun demikian ada potensi perlakuan yang menghasilkan jumlah tunas paling besar yaitu perlakuan penyiraman dengan konsentrasi air kelapa 50 \% (Gambar 2). Menurut Budiono (2004), pemberian air kelapa sampai 20\% mampu meningkatkan pertambahan jumlah tunas dan jumlah daun bawang merah dari in vitro.

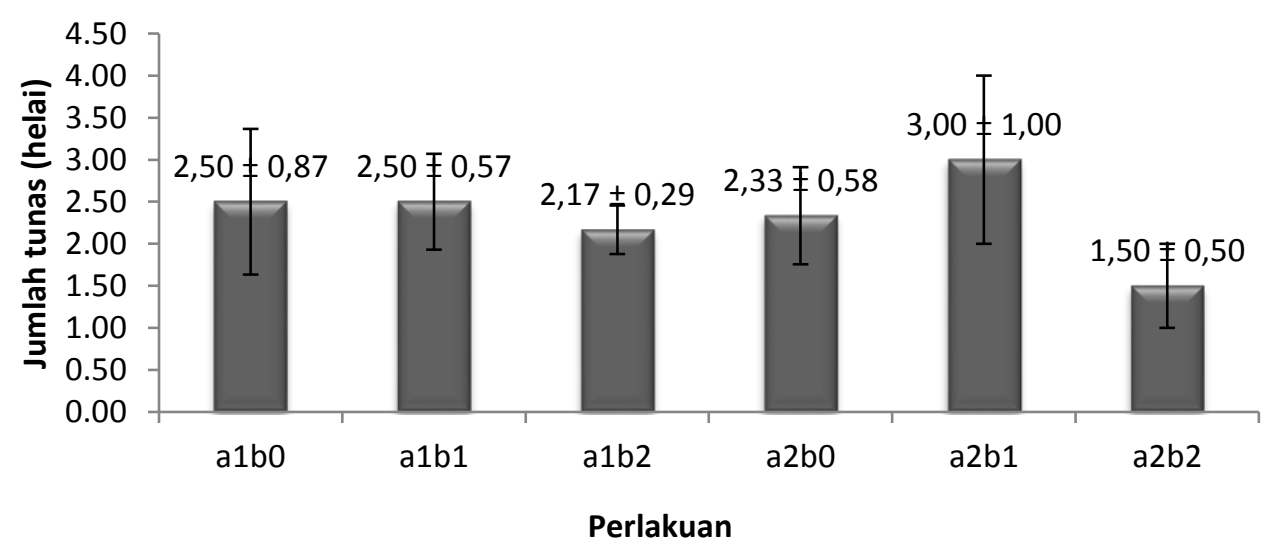

Gambar 2. Pengaruh perlakuan cara pemberian dan konsentrasi air kelapa pada jumlah tunas setek batang buah naga merah umur 10 MST (minggu setelah tanam) 
Panjang Tunas. Hasil analisis ragam menunjukkan bahwa semua perlakuan yang diaplikasikan tidak memberikan pengaruh yang signifikan pada variabel panjang tunas. Rata-rata panjang tunas adalah 28,88 $\mathrm{cm}$. Walaupun demikian ada potensi perlakuan yang menghasilkan panjang tunas paling besar yaitu perlakuan penyiraman dengan konsentrasi air kelapa 50 \% (Gambar 3). Menurut Salisbury dan Ross (1995), sitokinin eksogen dapat memacu pembentangan sel pada daun muda. Wareing dan Phillips (1981) menyatakan bahwa auksin merupakan sinyal korelatif yang mempengaruhi sintesis sitokinin. Apabila auksin berkurang, sitokinin meningkat, akibatnya tunas lateral berkembang.

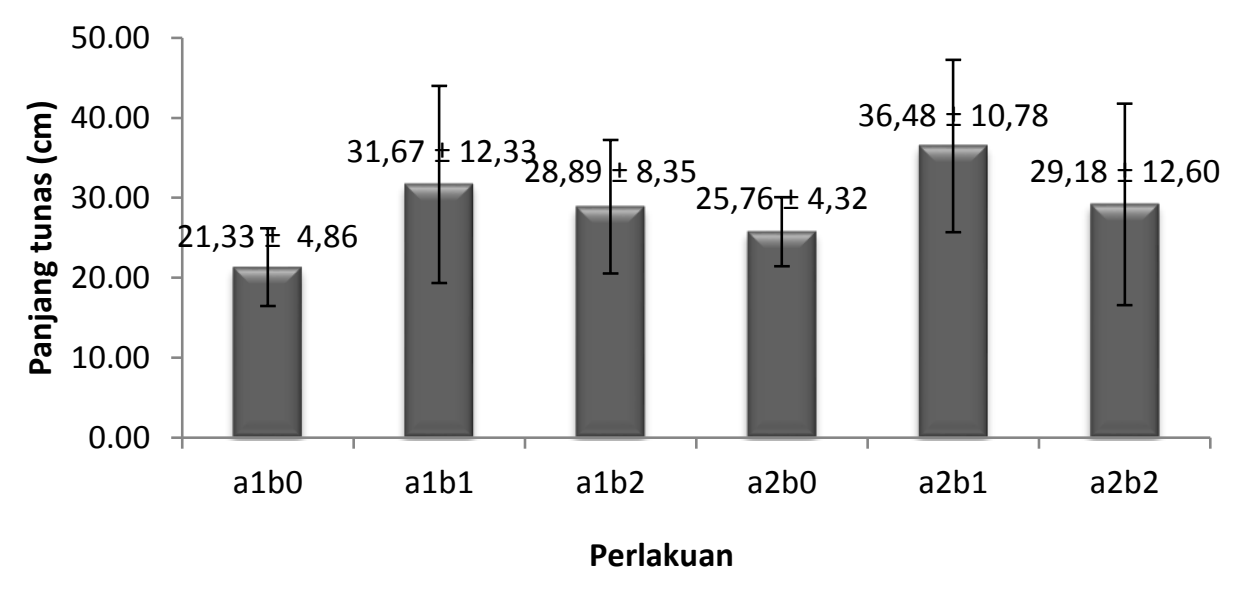

Gambar 3. Pengaruh perlakuan cara pemberian dan konsentrasi air kelapa pada panjang tunas setek batang buah naga merah umur 10 MST (minggu setelah tanam)

Hasil analisis ragam menunjukkan bahwa pengelompokkan berdasarkan bobot bahan setek memberikan pengaruh yang signifikan pada panjang tunas. Rata-rata panjang tunas yang paling besar dicapai pada kelompok III (bobot setek terbesar antara 119-178 g) dengan rerata sebesar 35,61 cm (Gambar 4).

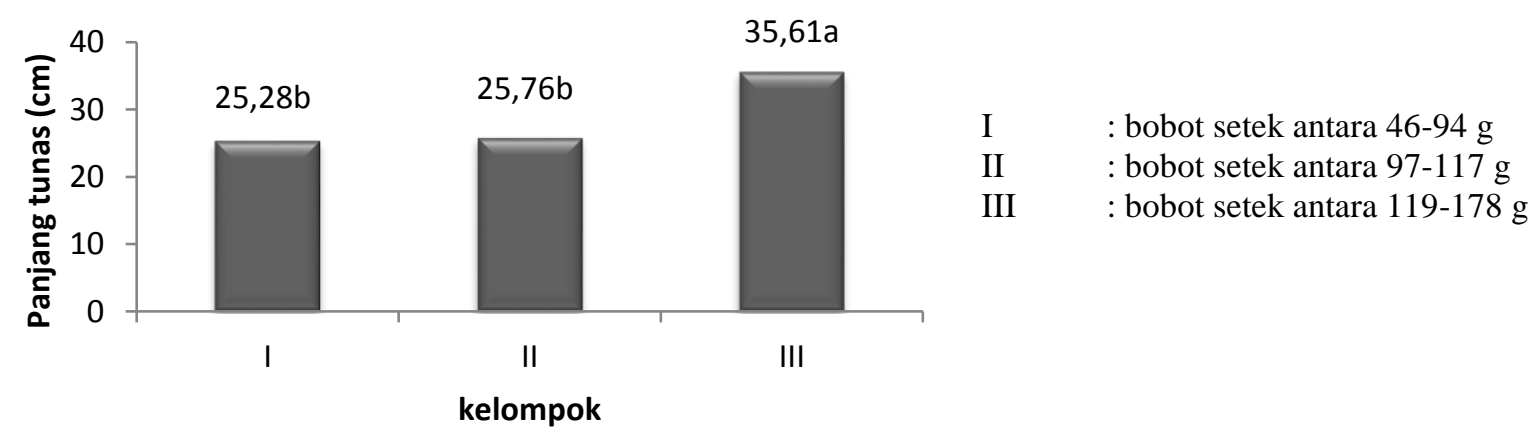

Gambar 4. Pengaruh pengelompokkan pada panjang tunas setek batang buah naga merah umur 10 MST (minggu setelah tanam). Nilai tengah yang diikuti dengan huruf yang sama tidak berbeda nyata dengan uji BNT pada $0,05\left(\mathrm{BNT}_{\text {transformasi }}=0,87\right)$

Keterangan : 
Bobot Tunas. Hasil analisis ragam pada variabel bobot tunas menunjukkan bahwa konsentrasi air kelapa dapat meningkatkan bobot tunas secara signifikan. Bobot tunas pada akhir percobaan yang menunjukkan hasil tertinggi adalah 147,67 g yang dicapai pada konsentrasi air kelapa $50 \%$ (Gambar 5). Berdasarkan penelitian Sujarwati (2011) bahwa pemberian air kelapa mampu meningkatkan pertumbuhan bibit palem putri. Pertumbuhan bibit palem mulai meningkat pada penggunaan air kelapa dengan konsentrasi 50\%. Hal ini disebabkan air kelapa pada konsentrasi 50\% mengakibatkan peningkatan jumlah sitokinin yang optimal, sehingga merangsang pembelahan sel. Berdasarkan hasil analisis kandungan kimia air kelapa oleh Kristina dan Shahid (2012) menunjukkan bahwa komposisi ZPT kinetin (sitokinin) dalam air kelapa muda adalah 273,62 mg/l dan zeatin 290,47 mg/l, sedangkan kandungan IAA (auksin) adalah 198,55 $\mathrm{mg} / \mathrm{l}$.

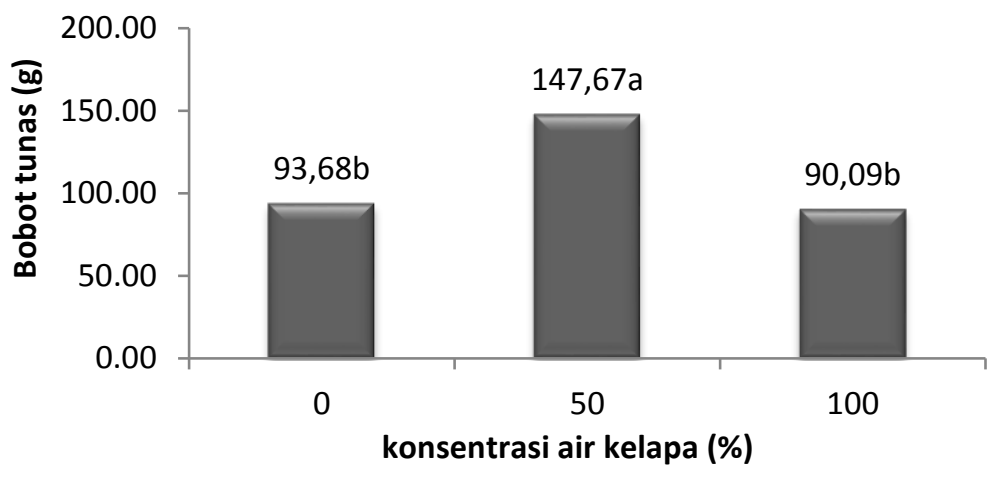

Gambar 5. Pengaruh perlakuan konsentrasi air kelapa pada bobot tunas setek batang buah naga merah umur 10 MST (minggu setelah tanam). Nilai tengah yang diikuti dengan huruf yang sama tidak berbeda nyata dengan uji BNT pada $0,05\left(\mathrm{BNT}_{\text {transformasi }}=0,18\right)$

Hasil analisis ragam menunjukkan bahwa pengelompokkan berdasarkan bobot bahan setek memberikan pengaruh yang signifikan pada bobot tunas. Rata-rata bobot tunas yang paling besar dicapai pada kelompok III (bobot setek terbesar antara 119-178 g) dengan rerata sebesar 147,00 g (Gambar 6). Hal ini karena bobot setek yang besar mengandung karbohidrat yang lebih banyak sehingga mampu meningkatkan bobot tunas pada setek.

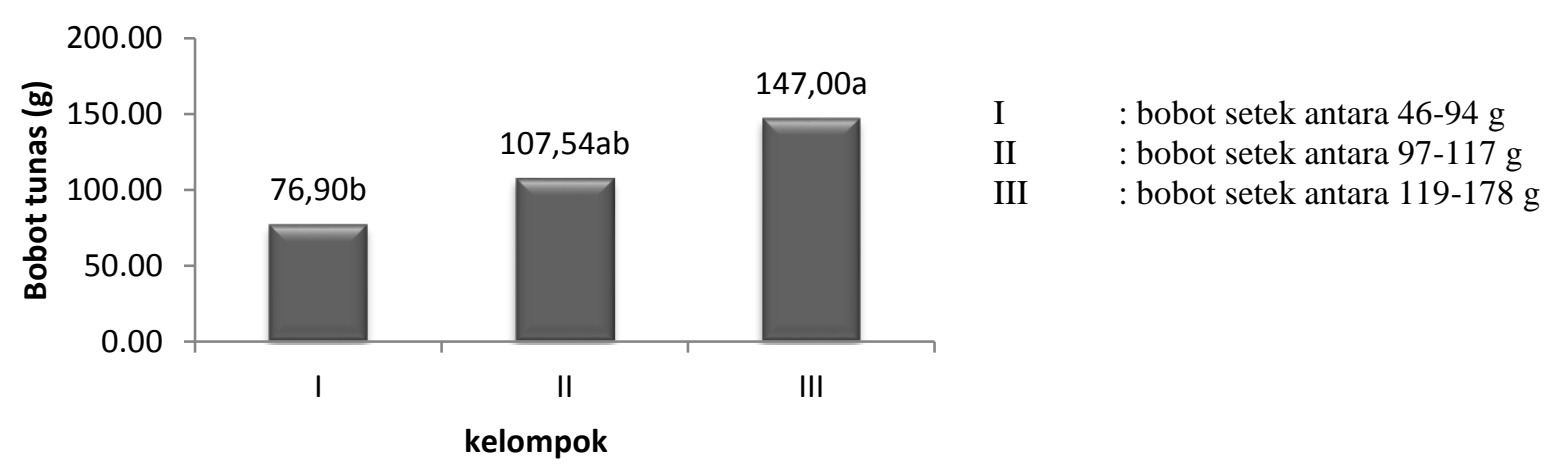

Gambar 6. Pengaruh pengelompokkan pada bobot tunas setek batang buah naga merah umur 10 MST (minggu setelah tanam). Nilai tengah yang diikuti dengan huruf yang sama tidak berbeda nyata dengan uji BNT pada $0,05\left(\mathrm{BNT}_{\text {transformasi }}=0,18\right)$ 
Jumlah Akar Primer. Hasil analisis ragam pada variabel jumlah akar primer menunjukkan bahwa konsentrasi air kelapa dapat meningkatkan jumlah akar primer secara signifikan. Jumlah akar primer pada akhir percobaan yang menunjukkan hasil terbanyak adalah 3,25 helai yang dicapai pada konsentrasi air kelapa $50 \%$ (Gambar 7). Perkembangan akar terjadi karena adanya pergerakan ke bawah oleh auksin, karbohidrat dan rooting cofactor (zat-zat yang berinteraksi dengan auksin yang mengakibatkan tumbuhnya akar) dari tunas ke arah dasar setek (Rochiman dan Harjadi, 1973). Selanjutnya, zat-zat ini akan menstimulir pembentukan akar pada setek. Zat tersebut akan mempengaruhi pertumbuhan akar yang ditunjukkan dengan semakin banyaknya jumlah akar pada setek. Semakin banyak jumlah akar yang terbentuk, semakin memudahkan tanaman dalam menjalankan fungsinya, salah satunya dalam penyerapan unsur hara.

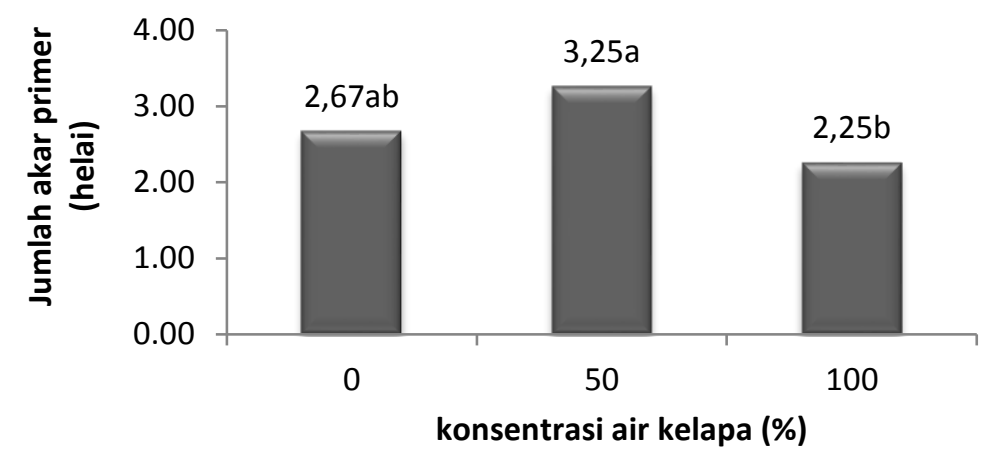

Gambar 7. Pengaruh perlakuan konsentrasi air kelapa pada jumlah akar primer setek batang buah naga merah umur 10 MST (minggu setelah tanam). Nilai tengah yang diikuti dengan huruf yang sama tidak berbeda nyata dengan uji BNT pada $0,05\left(\mathrm{BNT}_{\text {data asli }}=0,73\right)$

Panjang Akar Primer. Hasil analisis ragam menunjukkan bahwa semua perlakuan yang diaplikasikan tidak memberikan pengaruh yang signifikan pada variabel panjang akar primer. Rata-rata panjang akar primer adalah 14,92 $\mathrm{cm}$ (Gambar 8). Panjang akar merupakan hasil perpanjangan sel-sel di belakang meristem ujung, sedangkan lebar yang lebih daripada pembesaran sel-sel ujung merupakan hasil dari meristem lateral atau pembentukan kambium yang memulai pertumbuhan sekunder dari meristem kambium. Meristem akar mampu melaksanakan pertumbuhan yang kontinu, tidak terbatas pada akibat pelebaran akar untuk periode yang secara potensial tidak terbatas (Gardner et al., 1991).

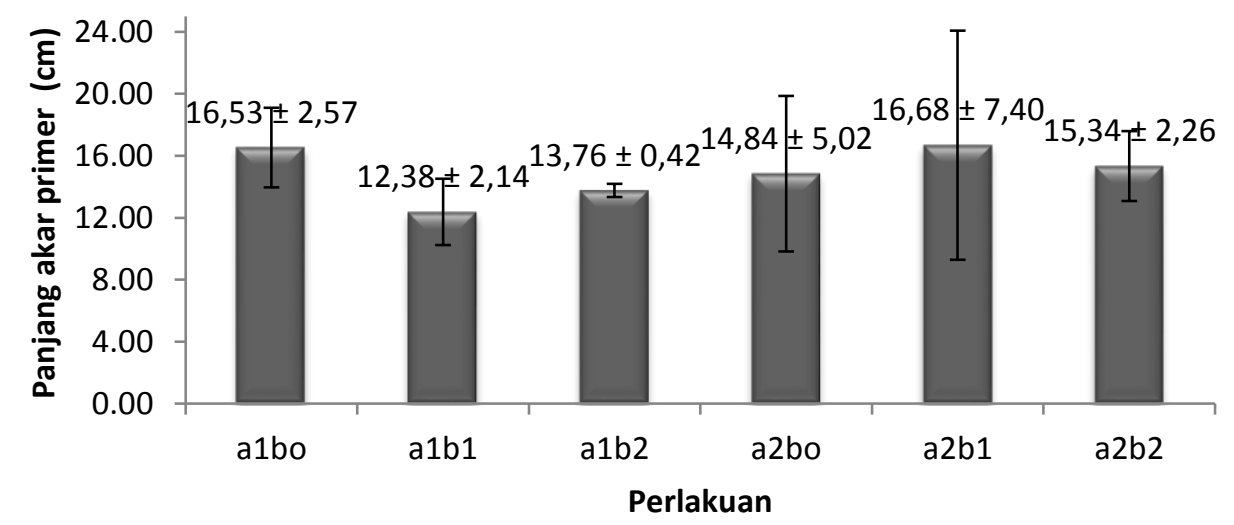

Gambar 8. Pengaruh perlakuan cara pemberian dan konsentrasi air kelapa pada panjang akar primer setek batang buah naga merah umur 10 MST (minggu setelah tanam) 
Bobot Kering Akar. Hasil analisis ragam menunjukkan bahwa semua perlakuan yang diaplikasikan tidak memberikan pengaruh yang signifikan pada variabel bobot kering akar. Rata-rata bobot kering akar adalah $0,27 \mathrm{~g}$. Walaupun demikian ada potensi perlakuan yang menghasilkan bobot kering akar paling besar yaitu perlakuan penyiraman dengan konsentrasi air kelapa $50 \%$ (Gambar 9). Berat kering tanaman adalah berat tanaman setelah dikeringkan dalam oven, sehingga kadar airnya telah hilang dan yang tersisa hanya senyawa-senyawa kimia yang terkandung dalam tanaman. Nyakpa et al. (1988) menjelaskan bahwa pertumbuhan tanaman dicirikan dengan berat kering tanaman. Ketersediaan hara yang kurang bagi tanaman akan diikuti penurunan aktifitas fotosintesis yang menghasilkan asimilat sedikit, akhirnya berat kering menjadi kecil yang hubungannya terhadap laju pertumbuhan tanaman.

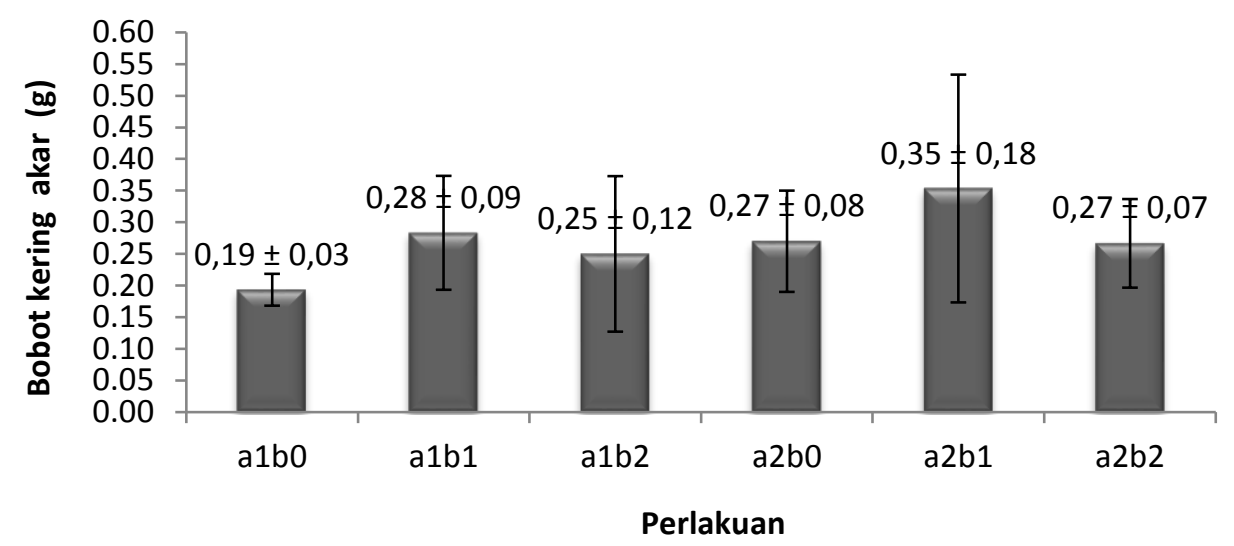

Gambar 9. Pengaruh perlakuan cara pemberian dan konsentrasi air kelapa pada bobot kering akar setek

\section{KESIMPULAN DAN SARAN}

Berdasarkan hasil penelitian yang telah dilakukan, maka dapat diambil kesimpulan bahwa cara perendaman dan penyiraman tidak memberikan pengaruh yang berbeda terhadap pertumbuhan setek batang buah naga merah. Pemberian air kelapa dengan konsentrasi $50 \%$ mampu meningkatkan bobot tunas sebesar 53,99 g dan jumlah akar primer sebanyak 0,58 helai pada setek batang buah naga merah. Sehingga pada penelitian berikutnya dapat dicoba penggunaan konsentrasi air kelapa dengan rentang konsentrasi yang lebih kecil seperti $0 \%, 25 \%, 50 \%, 75 \%$,dan 100\%. Pemilihan bahan setek buah naga yang baik menggunakan bagian pangkal cabang tanaman dengan bobot yang besar dan seragam. Apabila akan melakukan metode penyiraman dapat dicoba dengan frekuensi penyiraman 6 kali dengan selang penyiraman 3 hari.

\section{DAFTAR PUSTAKA}

Budiono, D. P. 2004. Multiplikasi in vitro tunas bawang merah (Allium ascalonicum L) pada berbagai taraf konsentrasi air kelapa. J. Agronomi 8 (2) : 75-80.

Febriana, S. 2009. Pengaruh konsentrasi ZPT dan panjang stek terhadap pembentukan akar dan tunas pada stek apokad (Persea americana Mill). (Skripsi). Institut Pertanian Bogor. Bogor. 72 hlm.

Gardner, F.P., R.B. Pearce, and R.L. Mitchell. 1991. Fisiologi Tanaman Budidaya. Terjemahan oleh H. Susilo. Universitas Indonesia (UI Press). Jakarta. $428 \mathrm{hlm}$.

Hartmann, H. T., D. E. Kester, F. T. Davies, dan R. L. Geneve. 1997. Plant Propagation (6th Edition) by Cutting. Upper Saddle River. New Jersey. P. 276-327 
Kristina, N. N dan S F Syahid. 2012. Pengaruh air kelapa terhadap multiplikasi tunas in vitro, produksi rimpang, dan kandungan xanthorrhizol temulawak di lapangan. J. Penelitian Tanaman Industri. 18 (3) : $125-134$

Nyakpa, M. Y., A.M. Lubis, M.A. Pulung, A.G. Amran, A. Munawar, G. B. Hong, N.Hakim. 1988. Kesuburan Tanah. Universitas Lampung, Lampung.

Rochiman K dan SS Harjadi. 1973. Pembiakan Vegetatif. Departemen Agronomi.Fakultas Pertanian. Institut Pertanian Bogor. 185 hlm.

Salisbury FB dan CW Ross. 1995. Fisiologi Tumbuhan, Perkembangan Tumbuhan dan Fisiologi Lingkungan. Jilid Tiga. Terj. D.R. Lukman \& Sumaryono. ITB. Bandung.

Satria, F., 2011. Pengaruh beberapa konsentrasi atonik pada pertumbuhan setek buah naga berdaging merah (Hylocereus costaricensis (Web) Britton \& Rose). (Skripsi). Universitas Andalas. Padang. 76 hlm.

Sujarwati, S Fathonah, E Johani dan Herlina. 2011. Penggunaan air kelapa untukmeningkatkan perkecambahan dan pertumbuhan palem putri (Veitchia Merilli). J. Sagu. 10 (1) : 24-28.

Tim Karya Tani Mandiri. 2010. Pedoman Bertanam Buah Naga. CV. Nuansa Aulia, Bandung. 152 hlm.

Wareing, P.F and J. D.J Phillips. 1981. Growth and Diferentiation in Plants. Third edition. Pergamon Press. Oxford. $421 \mathrm{hlm}$.

Winarsih, S. 2007. Mengenal dan Membudidayakan Buah Naga. Aneka Ilmu,Semarang. 240 hlm. 